hospital facilities in Galway/Dublin (Audiology, sleep study) were on average after a waiting period of 19.6 weeks.

Conclusion There was an ease of access for local services available to patients with neurodisability. Specialised setups took longer time providing the service.

\section{G632 EFFECTIVENESS OF CANNABIDIOL OIL IN THE MANAGEMENT OF ADHD AND ITS CO-MORBIDITIES: REVIEW OF THE EVIDENCE}

\begin{abstract}
${ }^{1,2}$ Hani F Ayyash, ${ }^{3}$ Michael Ogundele, ${ }^{1}$ Bertha Calles Cartas, ${ }^{4,5}$ Maissa Dahabra. ${ }^{1}$ Mid and South Essex University Hospitals Group, Southend University Hospital NHS Foundation Trust, Southend-On-Sea, UK; ${ }^{2}$ Scientific Member, British Paediatric Surveillance Unit, Royal College of Paediatrics and Child Health, UK; ${ }^{3}$ Bridgewater Community Healthcare NHS Foundation Trust, Halton, Liverpool, UK; ${ }^{4}$ Faculty of Pharmacy, Applied Science University, Amman, Jordan; ${ }^{5}$ Al Radwan Community Pharmacy, Amman, Jordan
\end{abstract}

\subsection{6/archdischild-2020-rcpch.546}

Aims Attention deficit Hyperactivity Disorder (ADHD) is the commonest neurobehavioural disorder diagnosed in childhood with a chronic course extending into adulthood in at least a third of the patients. There are ongoing controversies about the safety and efficacy of chronic use of CBD in children and adults.

We aimed to identify best evidence from published literature for effectiveness of cannabinoid products in controlling symptoms of ADHD and its associated common comorbidities.

Methods We systematically searched several health and social science databasses for relevant published articles using keywords including 'Attention Deficit Hyperactivity Disorder', 'ADHD', 'Disruptive Behaviour Disorders', 'cannabinoids', 'cannabidiol', 'cannabi“' and 'CBD'.

Results $7 / 11$ relevant papers were related to adults while 4 were about children and young people (CYP) with ADHD. There is a dose-related association between chronic heavy regular use of cannabis and ADHD symptoms in adults. This is likely due to many adult ADHD patient self-medicating with cannabis. Chronic abuse of Cannabis is associated with abuse of other substances, including ecstasy (MDMA) and methamphetamines.

Limited RCT against placebo showed positive effect of $\mathrm{CBD}$ in improving core $\mathrm{ADHD}$ symptoms among adults over a 6 week period with no negative effect on cognitive function. Limited study of CBD-based medicines, given as adjunct to pharmaco- and psychotherapy, suggest promising improvement in the symptoms of ADHD and many co-morbid mental, social, communication, behavioral and motor disorders in adults.

The dearth of research evidence among CYP as well as the knowledge of significant differences between the level of maturation and plasticity of the adolescent brain makes it impossible to extrapolate any beneficial effect of CBD use in adults to adolescents and younger children for management of ADHD and its common comorbidities.

Conclusion There is insufficient research evidence to support recommendation of CBD products in CYP for ADHD management in both children and adults. Positive effects of $\mathrm{CBD}$ on $\mathrm{ADHD}$ and other $\mathrm{MH}$ disorders have been found in short-term studies but more chronic CBD abuse has often been associated with detrimental effects on cognitive functioning, educational achievement and employment prospects.

\section{Late additions}

\section{G139(P) EARNEST (EARLY ASSESSMENT AND REFERRAL OF NEWBORNS ENABLING SAFER TRIAGE) PROTOCOL PROMOTING NEONATAL TEAM SPIRIT AND EARLY RECOVERY OF NEWBORN}

${ }^{1} \mathrm{M}$ Sahai, ${ }^{1} \mathrm{GK}$ Goyal, ${ }^{2} \mathrm{~K}$ Gupta. ${ }^{1}$ Pediatrics Department, RUHS College of Medical Sciences, Jaipur, India; ${ }^{2}$ Department of PSM, RUHS College of Medical Sciences, Jaipur, India

\subsection{6/archdischild-2020-rcpch.547}

Objective EARNEST protocol devised by the author was tested for its impact in improving newborn care.

Method This pilot study was carried out over 3 months in the neonatal triage of a district hospital. All newborns being brought to the Triage area here were assessed using this protocol and its user friendliness scored using 'SMART' criteria. Study group comprised of 100 newborns [Group A] where. EARNEST was applied after the institution of the NRP Protocol For comparison [Group B], 100 matched newborns, admitted in the same duration, where only NRP protocol was applied.

Result Among Group A newborns, better documentation of data was reported as compared to group B $[p<0.05]$, duration of hospitalization for less than 10 days was seen in $63 \%$ patients in group A as compared to $41 \%$ in Group B patients [p value 0.002].The EARNEST protocol helped decrease the time required for a detailed neonatal triage assessment, instituting early therapeutic intervention and referral to a higher centre if required $[\mathrm{p}=0.04]$.

\begin{tabular}{llll} 
Abstract G139(P) Table 1 & & \\
\hline Score: & $<2$ & $\mathbf{2 - 4}$ & $\mathbf{5}$ \\
\hline Specific & 0 & $95 \%[19]$ & $5 \%[1]$ \\
Measurable & 0 & $95 \%[19]$ & $5 \%[1]$ \\
Achievable & 0 & $85 \%[17]$ & $15 \%[3]$ \\
Realistic & 0 & $70 \%[14]$ & $30 \%[6]$ \\
Time saving & 0 & $30 \%[6]$ & $70 \%[14]$ \\
Total score & $\leq 10$ & $11-20$ & $21-29$ \\
Participants having this score & 0 & $75 \%[15]$ & $15 \%[5]$ \\
\hline
\end{tabular}

Conclusion The use of this protocol where a newborn's profile is entered under the 6 main headings of i) Patient profile - by the nursing staff. ii) Problems in baby - by first year resident, iii) Progress of Baby - by second year resident iv) Plan of management and v) Prognosis - by senior resident and vi) Professional advice by the consultant has empowered the Neonatal Triage team in conducting an easily recordable, reproducible newborn assessment with division of work, team spirit and early detection of complications and referral if required.

\section{G517(P) PAEDIATRIC WEIGHT MANAGEMENT SERVICE IN THE DISTRICT GENERAL HOSPITAL - IS IT A TIER-3 SERVICE?}

M Mallya, U Niranjan. Paediatrics, Luton and Dunstable University Hospital, Luton, UK

\subsection{6/archdischild-2020-rcpch.548}

Aims Childhood obesity is a significant health burden, with limited resources to manage severe obesity including co- 